\title{
Long-term outcomes of distal locking in extracapsular fractures treated with trochanteric Gamma3 nails
}

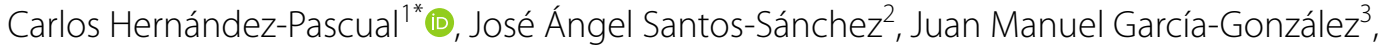 \\ Carlos Fernando Silva-Viamonte ${ }^{4}$, Carmen Pablos-Hernández ${ }^{5}$, Luis Ramos-Pascua ${ }^{6}$ and \\ José Antonio Mirón-Canelo ${ }^{7}$
}

\begin{abstract}
Background: Few publications have assessed long-term results of distal locking of short endomedullary nails for extracapsular hip fracture. Virtually all of them focus on immediate differences. Criteria for the use of static or dynamic locking are unclear in most nailing systems, and use is advised in unstable fracture patterns or with risk of bell-clapper effect, but often influenced by the "orthopaedic school".

Materials and methods: This is a historical cohort study on patients diagnosed and operated in 2014 and followed up until endpoint, considered as consolidation or major complication, plus evaluation of overall long-term survival. They were categorised as static distal locking (ST) or dynamic distal locking (DN). Both are comparable, except for all stable pre-operative classifications, Fracture Mobility Score (FMS) at discharge, and immediate post-operative loading, all of which were in favour of DN.

Results: Consolidation took place in $>95 \%$ of patients, with a non-statistically significant delay trend in ST. Less than $6 \%$ in both ST and DN had major complications, with no differences. Most cases suffered early cut-out. Significant fracture collapse was the most frequent minor complication. There were more statistically significant minor and total complications in ST. Infection, without differences, can precede cut-out. Lateral thigh pain was similar and could be related to back-out. In DN, $21.1 \%$ of cases were truly dynamised. We did not find differences in mobility or in longterm survival.

Conclusions: Any type of distal locking seems to be safe for consolidation, despite a slightly longer consolidation time in static locking. Early cut-out was the main complication, while others were very infrequent, which is an advantage over helical blade devices. There was a higher rate of minor and overall mechanical complications in ST, but infection and lateral thigh pain were similar. Most non-traumatic mechanical complications occurred around 5-6 weeks. About one in five of the DN truly dynamised, with all cases occurring before 8 weeks. Mobility until endpoint and overall long-term survival were not influenced by the locking mode used.
\end{abstract}

Level of evidence: Therapeutic study, level 2b.

Keywords: Intertrochanteric fracture, Gamma3, Distal locking, Consolidation, Mechanical complications, Cut-out, Risk factor

\footnotetext{
*Correspondence: chernandezp@saludcastillayleon.es

${ }^{1}$ Department of Trauma and Orthopaedic Surgery, Hospital Universitario

de Salamanca, Pso. San Vicente 58-182, 37004 Salamanca, Spain

Full list of author information is available at the end of the article
}

\section{Background}

Osteoporotic hip fractures occur mainly in elderly people, and they carry a high mortality, up to $50 \%$ in patients with marked comorbidity [1]. In Spain, they are one of 
the main causes of admission and hospital stays [26]. The ageing of the population has turned this issue into a problem for the public health systems in developed countries [30], and it even led to the development of orthogeriatrics [48]. The treatment of extracapsular fractures (ECF) of the proximal femur is under universal consensus with strong evidence for management. They occur in cancellous, well-vascularised bone, with low risk of non-union; therefore, their treatment consists of reduction and osteosynthesis, reserving conservative treatment for patients unfit for anaesthesia [48]. Internal reduction-fixation is the treatment of choice over arthroplasty [10, 32]. An ideal implant must be easy to manage and allow complete immediate post-operative loading by sufficient fragment fixation. Dynamic Hip Screw (DHS) is the gold standard in ECF deemed as stable, whereas cephalomedullary nails are preferentially used in unstable ones [34]. Nevertheless, ease of use, familiarity technique, shorter surgery time and difficulty to define intra-operative stability has recently encouraged many surgeons to use intramedullary nails for all, though not without some controversy $[53,57]$.

Varus malreduction [39], ECF extension to the femoral neck [13], posterior subtype of Ikuta's classification [8], vertical shear fractures [21] and intra-operative breakage/ lack of lateral wall competency [59] have recently been added to classic instability elements of ECF: insufficient posteromedial cortical contact, avulsion of lesser trochanter, subtrochanteric extension, and reverse fracture line $[6,63]$. In classic basicervical or "basicervical-equivalent" ECF, inter-fragmentary rotation is considered, so an anti-rotation device before definitive fixation is widely accepted [57]. Subtrochanteric extension of ECF determines the selection of a short or long nail, without consensus on ideal nail length [7]. In short nails, type of distal locking has not been considered in patient's safety. Few publications, most of them retrospective and with low statistical power, can be found using long nails [63], long/ short nails mixed indiscriminately [6], one single locking mode, or excluding some types of fractures, such as AO Foundation/Orthopaedic Trauma Association (AO/ OTA) type A3 ones [39]. Some studies suggest dynamic locking implies higher complications [13], unlike those which report that the static approach causes further shortening, with subsequent risk of Trendelenburg gait $[8,21]$. Most surgical techniques indicate them if there is risk of bell-clapper effect and in unstable ones, but it is necessary to differentiate pre- and intra-operative stability, so in the end, it is up to the surgeon in charge or the "orthopaedic school" he/she was trained in $[59,63]$.

Our overall goal is to find out whether the locking mode, using an internationally recognised short nail with a single cephalic screw, has any role in consolidation, in the non-traumatic mechanical complications (NTMC), or in infection and lateral thigh pain in ECF. Our specific objectives are to detect dynamisation and possible influence on mobility and overall long-term survival. Our null hypothesis is that the type of distal locking does not influence fracture consolidation, NTMC, infection or lateral thigh pain, as well as mobility or long-term survival.

\section{Materials and methods}

This was a historical cohort study of patients exposed to surgery for extracapsular hip fractures diagnosed in our Orthopaedic Surgery and Traumatology unit; patients were older than 65 years old in 2014. The clinical research work was done at Hospital Universitario de Salamanca, a third-level university hospital and regional reference centre. This study was approved by the hospital's research ethics committee. At least one of the following characteristics had to be met as an endpoint:

(a) Consolidation: absence of groin pain and trabeculae pass in fracture fragments, greater than $50 \%$ in both radiological projections.

(b) Major mechanical complication: one which, at least potentially, requires a new surgical intervention on the affected hip for its resolution.

The organigram in Fig. 1 outlines the sample collection method, with inclusion and exclusion criteria. The study was carried out with 208 titanium Gamma3 trochanteric nails (hereafter referred to as Gamma3T) - length $180 \mathrm{~mm}$ and distal width $11 \mathrm{~mm}$, neck-shaft angle between $120^{\circ}$ and $130^{\circ}$, by Stryker Trauma GmbH, Schörnkirchen, Germany; a total of 151 in static locking mode (referred to as ST) and 57 in dynamic locking mode (referred to as DN). Due to their scarce representativeness and the difficulty to interpret dynamisation, the ten unlocked (UL) cases were discarded (Fig. 1).

All cases occurred in different people, except one that needed bilateral ST surgery (3 months passed between both interventions, but an endpoint criterion was met in each). All were performed by close reduction, except for two $(0.96 \%)$, which needed open reduction and cerclage wiring. No anti-rotation implant was used apart from a proximal locking device (PLD). Set screw was unscrewed by one-quarter of a turn after slightly tightening in all cases. Distal locking mode was based on the surgeon's preferences, according to fracture's stability and surgical technique. In Gamma3T nails, distal locking is indicated "to be used generally in dynamic mode, and in static mode only when the fracture is considered unstable, when the nail size does not fit the medullary canal size, or when there is a risk of interfragmentary rotation". Distal screw did not fit distal hole in two cases. One was left as it was and was considered DN, the other case was correctly replaced as ST and was considered ST. 


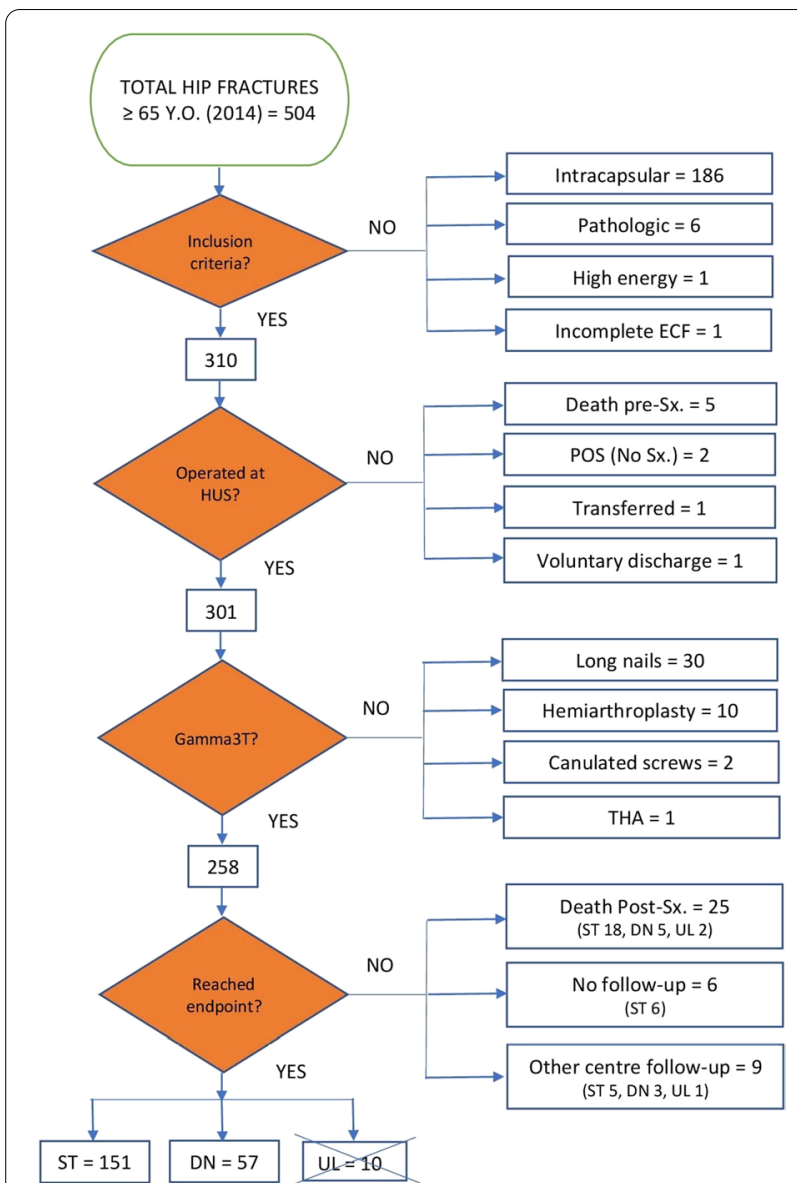

Fig. 1 Organisation chart. ECF, extracapsular fracture; HUS, Hospital Universitario de Salamanca; Sx., surgery; POS, poor overall status; THA, total hip arthroplasty; ST, static locking mode; DN, dynamic locking mode; UL, unlocked mode

Pre-operative and peri-operative variables were obtained from clinical records, including serial blood tests and immediate pre-operative and post-operative radiological studies (anteroposterior projection of the pelvis and axial projection of the affected hip) as well as dependence and mobility using Fracture Mobility Score (FMS) [62]. Similar x-rays were obtained at each followup visit, if conducted. Partial weight bearing (PWB) with crutches or walker was allowed if a good reduction was considered by Fogagnolo criteria [24] immediately after surgery, or after first check-up. Post-discharge follow-up consisted of standard clinical-radiological check-up visits at first, third, fifth, ninth and twelfth month ( \pm 1 week) after discharge, which concluded once the endpoint was reached. At each visit, they were evaluated with regard to pain at the fracture site, surgical wound and mobility using FMS [62]. No one was classified in the unknown item of the FMS scale, since according to the organisation chart (Fig. 1), patients who did not complete an endpoint were excluded. All complications were registered at the time they were diagnosed, as well as major complications that finally consolidated.

We have divided NTMC into two categories: major (may require surgical reintervention) and minor (no require surgical reintervention). By major, we understand cut-out, cut-in, cut-through, pull-out, breakage, osteonecrosis and pseudo-arthrosis, and by minor, we understand fracture collapse (also called caput-collum shortening or back-out) and loss of reduction. The last two can be combined. Significant fracture collapse was considered equal to or greater than $1 \mathrm{~cm}$, as previously established by Zlowodzki [66] and Fang [21]. We have classified them as early mechanical complications (EMC) or late mechanical complications (LMC), depending on whether they occur within 6 months post-operatively or later, which is between the 3 months proposed by Bojan [7] and the first year indicated by Ehlinger [19].

Doppelt's method [17] was used to detect non-obvious radiological complications and to measure tip-apex distance (TAD), given that diameter of cephalic screw is known $(10.5 \mathrm{~mm})$. Cleveland classification was used in immediate post-operative $\mathrm{x}$-rays.

Other complications were recorded in clinical records. Infection met the confirmatory criteria to be assessed as an infection after fracture fixation (IAFF), as proposed by Metsemakers et al. [47]. Lateral thigh pain was considered when such pain was reported during follow-up, without association with new trauma or IAFF.

For the identification of the number of deaths during the follow-up period, we consulted the national death rate of the Spanish Ministry of Health at the end of February 2020 [to eliminate possible bias due to the emerging coronavirus disease 2019 (COVID-19) pandemic].

Regarding peri-operative variables, there are significant differences in all pre-operative classification systems (Jensen [29], AO/OTA until 2017 [42] and Massoud [44]), with ST being used more often in unstable fractures and $\mathrm{DN}$ in stable fractures. There are also significant differences in immediate post-operative loading, allowed more often in DN. There are no differences in TAD [4] or position according to Cleveland [14]. We also observed no differences in the post-operative Fogagnolo classification [24] (Table 1).

\section{Statistical analysis}

Descriptive statistics generated using SPSS 20.0 (SPSS, Inc., Chicago, IL, USA) were utilised for data analysis. Kolmogorov-Smirnov tests were used to evaluate the Gaussian distributions of continuous variables, and comparisons were performed with Mann-Whitney $U$ tests. For categorical variables, Pearson chi-square tests and Fisher's exact tests were used, and for American Society 
Table 1 Peri-operative variables

\begin{tabular}{|c|c|c|c|}
\hline Peri-operative variables & Static distal locking (ST) & Dynamic distal locking (DN) & $p$ \\
\hline Number of cases & 151 & 57 & \\
\hline \multicolumn{4}{|l|}{ Pre-Sx. classifications } \\
\hline Jensen & & & $0.002^{\mathrm{a}^{*}}$ \\
\hline I: simple, non-displaced & $1(0.7 \%)$ & $4(7.0 \%)$ & \\
\hline II: simple or displaced basicervical & $45(29.8 \%)$ & $27(47.4 \%)$ & \\
\hline III: displaced, extended to GT & $10(6.6 \%)$ & $5(8.8 \%)$ & \\
\hline IV: displaced, extended to LT & $67(44.4 \%)$ & $17(29.8 \%)$ & \\
\hline V: displaced, extended to GT/LT & $28(18.5 \%)$ & $4(7.0 \%)$ & \\
\hline Stability (Jensen) & & & $0.001^{a^{*}}$ \\
\hline Stable $(I+I I)$ & $46(30.5 \%)$ & $31(54.3 \%)$ & \\
\hline Unstable $(I I I+I V+V)$ & $105(69.5 \%)$ & $26(45.6 \%)$ & \\
\hline AO/OTA 2007 & & & $0.008^{\mathrm{b}^{*}}$ \\
\hline A1 & $39(26.2 \%)$ & $24(50.0 \%)$ & \\
\hline$A 2$ & $93(62.4 \%)$ & $21(43.8 \%)$ & \\
\hline A3 & $17(11.4 \%)$ & $3(6.3 \%)$ & \\
\hline Stability (AO/OTA 2007) & & & $0.000^{b^{*}}$ \\
\hline Stable $(\mathrm{A} 1+\mathrm{A} 2.1)$ & $84(55.6 \%)$ & $39(68.4 \%)$ & \\
\hline Unstable $(\mathrm{A} 2.2+\mathrm{A} 2.3+\mathrm{A} 3)$ & $65(43.0 \%)$ & $9(15.8 \%)$ & \\
\hline "Pure" basicervical (B2.1) & $2(1.3 \%)$ & $9(15.8 \%)$ & \\
\hline Stability (Massoud) & & & $0.007^{b^{*}}$ \\
\hline Stable (Non-basicerv-equiv.) & $10(6.6 \%)$ & $11(19.3 \%)$ & \\
\hline Unstable (Basicerv-equiv.) & $141(93.4 \%)$ & $46(80.7 \%)$ & \\
\hline \multicolumn{4}{|l|}{ Medical } \\
\hline Average stay (days) & $9.71(S D 3.48)(4 ; 26)$ & 9.54 (SD 2.96) (4;20) & $0.985^{c}$ \\
\hline Pre-Sx. stay (days) & 3.45 (SD 2.62) $(0 ; 9)$ & $2.86($ SD 2.26) $(0 ; 7)$ & $0.130^{c}$ \\
\hline Post-Sx. stay (days) & $6.22(S D 2.81)(3 ; 25)$ & $6.67(S D 2.60)(3 ; 20)$ & $0.075^{c}$ \\
\hline Immediate post-Sx. PWB & & & $0.003^{\mathrm{b}^{*}}$ \\
\hline No & $90(59.6 \%)$ & $21(36.8 \%)$ & \\
\hline Yes & $61(40.4 \%)$ & $36(63.2 \%)$ & \\
\hline Estimated blood loss ( $\mathrm{g} / \mathrm{dl} \mathrm{Hb}$ ) & 1.816 (SD 1.79) (-3.5;5.8) & $2.260(S D 1.53)(-2.3 ; 5.9)$ & $0.140^{c}$ \\
\hline Total transfusions [Hem] & $1.31(\mathrm{SD} 1.40)(0 ; 8)$ & $1.281(S D 1.32)(0 ; 5)$ & $0.635^{c}$ \\
\hline Social situation & & & $0.518^{b}$ \\
\hline At home alone & $0(0 \%)$ & $0(0 \%)$ & \\
\hline At home accompanied & $64(42.4 \%)$ & $27(47.4 \%)$ & \\
\hline Institutionalised & $87(57.6 \%)$ & $30(52.6 \%)$ & \\
\hline Dependency & & & $0.483^{c}$ \\
\hline Barthel & 46.29 (SD 20.60) (10;80) & 48.68 (SD 21.74) (10;85) & \\
\hline \multicolumn{4}{|l|}{ Radiological } \\
\hline TAD & 22.958 (SD 6.50) (6.76;43.42) & 22.42 (SD 6.67) (10.78;39.49) & $0.647^{c}$ \\
\hline Cleveland quadrants (position) \% & & & $0.189^{b}$ \\
\hline Anterosuperior (1) & $4(2.6 \%)$ & $0(0 \%)$ & \\
\hline Superior-central (2) & $9(6.0 \%)$ & $0(0 \%)$ & \\
\hline Posterosuperior (3) & $0(0 \%)$ & $0(0 \%)$ & \\
\hline Anterior-central (4) & 15 (9.9\%) & $6(10.5 \%)$ & \\
\hline Centre-centre (5) & $86(57 \%)$ & $32(56.1 \%)$ & \\
\hline Posterior-central (6) & $8(5.3 \%)$ & $3(5.3 \%)$ & \\
\hline Anteroinferior (7) & $2(1.3 \%)$ & $0(0 \%)$ & \\
\hline Inferior-central (8) & $16(10.6 \%)$ & $6(10.5 \%)$ & \\
\hline Posteroinferior (9) & $11(7.3 \%)$ & 10 (17.5\%) & \\
\hline
\end{tabular}


Table 1 (continued)

\begin{tabular}{lll}
\hline Peri-operative variables & Static distal locking (ST) & Dynamic distal locking (DN) \\
\hline $\begin{array}{l}\text { C. Cleveland (centre versus no centre) } \\
\text { Centre-centre (5) }\end{array}$ & $86(57.0 \%)$ & $32(56.1 \%)$ \\
$\quad$ Rest of positions & $65(43.0 \%)$ & $25(43.9 \%)$ \\
Post-Sx. classifications & & \\
Fogagnolo & $9(6.0 \%)$ & $0.916^{\mathrm{b}}$ \\
$\quad$ Poor & $51(33.8 \%)$ & $17(29.8 \%)$ \\
Acceptable & $91(60.3 \%)$ & $40(70.2 \%)$ \\
Good &
\end{tabular}

Tests: ${ }^{\text {a }}$ Fisher's exact test. ${ }^{\mathrm{b}}$ Pearson's chi-square test. ${ }^{\mathrm{C}}$ Mann-Whitney $U$ test

GT, greater trochanter; LT, lesser trochanter; Sx., surgery; PWB, partial weight bearing

of Anesthesiologists (ASA) risk score, median's test was used. All $P$-values were two-sided, and $P$-values below 0.05 were considered significant. The Mantel-Cox logrank test was used to evaluate survival.

\section{Results}

Both groups are comparable in all pre-operative variables, non-modifiable (age, sex, fracture side) and modifiable (social situation, dependency according to Barthel's index [40], comorbidity according to Charlson's comorbidity score $[11,12]$, cognitive impairment according to Pffeifer's classification [43, 55], severe osteoporosis by previous fractures [50], previous osteoporosis treatment, anti-platelet therapy/anti-coagulation therapy (APT/ ACT) and ASA classification [22]) (Table 2).

\section{Consolidation}

Consolidation is the most common in both locking types, with percentages higher than $95 \%$. There is a mild, non-statistically significant trend towards longer time in the ST group versus the DN group (6.70 versus 6.07, $P=0.069)$.

\section{NTMC}

Less than $6 \%$ of cases had major radiological complications. The differences between ST and DN were not significant. Cut-out occurred in most cases (8 out of $11 ; 50 \%$ in ST and $100 \%$ in DN). One of them (ST) was considered as late. Out of the seven early cut-out cases, four were considered complete and three incomplete. There were three cases associated with infection after fracture fixation (IAAF). All early cases occurred in ST nailing (four cases) or non-dynamised DN nailing (three cases). One late cut-through, one osteonecrosis and one pseudoarthrosis (with an underlying coagulopathy) were also observed. Excluding late cases, average detection time was 5.8 weeks (ST) and 4.5 weeks (DN, with only three cases) $(P=0.699)$.

Great discrepancy was observed in minor complications, statistically significant in favour of ST $(56.3 \%$ versus $36.8 \%, P=0.028)$. The most frequent complication was clearly $>1 \mathrm{~cm}$ shortening (67 in ST, $78.8 \%$, versus 11 in $\mathrm{DN}, 52.4 \%$ ), followed by associated loss of reduction, and isolated loss of reduction. Once the three late cases $(2.83 \%)$ were excluded, average detection time was 5.5 weeks (5.62 in ST versus 5.42 in DN, $P=0.815$ ).

In total, radiological complications were statistically more frequent in ST than in DN (61.6\% versus $42.1 \%$, $P=0.012$ ), although generally speaking there were no differences regarding the time when they occur (5.63 ST versus 5.34 $\mathrm{DN}, P=0.938)$.

\section{Infection (IAFF)}

Ten cases of IAFF were reported (4.8\% in total), eight ST and two DN, with no differences between groups or in terms of diagnostic time (4.12 in ST versus 5.36 in DN, $P=0.188)$.

\section{Lateral thigh pain}

After excluding the cases of infection, 11 cases of lateral thigh pain (5.5\% in both groups) were also recorded during follow-up, with no significant differences. Their time of onset was highly variable, from a few weeks to more than 2 years. Eight cases occurred in ST settings, and three in $\mathrm{DN}$ cases that were not dynamised.

\section{Dynamisation}

Only $21.1 \%$ of the DN cases involved dynamisation, with 5.42 weeks on average and for no longer than 8 weeks (Table 3). 
Table 2 Pre-operative variables

\begin{tabular}{|c|c|c|c|}
\hline Pre-operative variables & ST & DN & $P$ \\
\hline Number of cases & 151 & 57 & \\
\hline \multicolumn{4}{|l|}{ Non-modifiable } \\
\hline Average age (years) & 85.50 (SD 6.87) (65;103) & 85.96 (SD 6.65) (65;96) & $0.359^{c}$ \\
\hline Sex (male/female) \% & & & $0.883^{b}$ \\
\hline Female & $118(78.1 \%)$ & $44(77.2 \%)$ & \\
\hline Male & $33(21.9 \%)$ & $13(22.8 \%)$ & \\
\hline Side & & & $0.621^{\mathrm{b}}$ \\
\hline Left & $64(42.4 \%)$ & $22(38.6 \%)$ & \\
\hline Right & $87(57.6 \%)$ & $35(61.4 \%)$ & \\
\hline \multicolumn{4}{|l|}{ Modifiable } \\
\hline Social situation & & & $0.886^{\mathrm{b}}$ \\
\hline At home alone & $22(14.6 \%)$ & $7(12.3 \%)$ & \\
\hline At home accompanied & $80(53.0 \%)$ & $30(52.6 \%)$ & \\
\hline Institutionalised & $49(32.5 \%)$ & $20(35.1 \%)$ & \\
\hline \multicolumn{4}{|l|}{ Dependency } \\
\hline Barthel's index & 74.47 (SD 22.24) (15;100) & 76.41 (SD 19.63) (10;100) & $0.823^{c}$ \\
\hline \multicolumn{4}{|l|}{ Comorbidity } \\
\hline Charlson Comorbidity Index (not age-adjusted) & $2.12(S D 1.36)(0 ; 7)$ & $2.25(\mathrm{SD} 1.04)(0 ; 4)$ & $0.209^{c}$ \\
\hline Charlson Comorbidity Index (age-adjusted) & 6.09 (SD 1.37) (4;11) & $6.17(\mathrm{SD} 1.05)(4 ; 8)$ & $0.277^{c}$ \\
\hline Cognitive impairment (Pfeiffer's) & & & $0.306^{\mathrm{b}}$ \\
\hline None & $28(18.5 \%)$ & $8(14.0 \%)$ & \\
\hline Mild & $97(64.2 \%)$ & $40(70.2 \%)$ & \\
\hline Moderate & $26(17.2 \%)$ & $8(14.0 \%)$ & \\
\hline Severe & $0(0 \%)$ & $1(1.8 \%)$ & \\
\hline Osteoporosis (previous fractures, Nuti's definition) & & & $0.769^{b}$ \\
\hline None & $85(56.3 \%)$ & $36(63.2 \%)$ & \\
\hline Traumatic (non-osteoporotic) & $5(3.3 \%)$ & $1(1.8 \%)$ & \\
\hline \multicolumn{4}{|l|}{ Osteoporotic: } \\
\hline Hip & $12(7.9 \%)$ & $3(5.3 \%)$ & \\
\hline Other locations & $38(28.6 \%)$ & $6(33.3 \%)$ & \\
\hline Both & $5(3.0 \%)$ & $3(5.3 \%)$ & \\
\hline Previous osteoporosis treatment* & & & $0.596^{\mathrm{b}}$ \\
\hline No & $129(85.4 \%)$ & $47(82.5 \%)$ & \\
\hline Yes & $22(14.6 \%)$ & $10(17.5 \%)$ & \\
\hline APT/ACT & & & $0.06^{b}$ \\
\hline None & $87(57.6 \%)$ & $32(56.1 \%)$ & \\
\hline Acetylsalicylic acid 100 mg & $23(15.2 \%)$ & $19(31.6 \%)$ & \\
\hline Acetylsalicylic acid 300 mg & $16(10.6 \%)$ & $1(1.8 \%)$ & \\
\hline Clopidogrel & $1(0.7 \%)$ & $0(0 \%)$ & \\
\hline Acenocumarol & $21(13.9 \%)$ & $5(8.8 \%)$ & \\
\hline Direct Xa inhibitors & $2(1.3 \%)$ & $1(2.2 \%)$ & \\
\hline LMWH & $1(0.7 \%)$ & $1(1.8 \%)$ & \\
\hline ASA Risk Score & $3(1 ; 4)$ & $2(1 ; 4)$ & $0.893^{d}$ \\
\hline
\end{tabular}

Tests: ${ }^{a}$ Fisher's exact test. ${ }^{b}$ Pearson's chi-square test. ${ }^{c}$ Mann-Whitney $U$ test. ${ }^{d}$ Median's test

APT, anti-platelet therapy; ACT, anti-coagulation therapy; LMWH, low molecular weight heparin; ASA, American Society of Anesthesiologists

*Upon admission, no calcium and/or vitamin D 
Table 3 Consolidation and post-operative complications detected

\begin{tabular}{|c|c|c|c|}
\hline Variable & ST & DN & $P$ \\
\hline Number of cases & 151 & 57 & \\
\hline \multicolumn{4}{|l|}{ Consolidation $^{1}$} \\
\hline Number of cases (\%) & $147(97.4 \%)$ & $55(96.5 \%)$ & $0.667^{\mathrm{a}}$ \\
\hline Weeks (average) ${ }^{1}$ & $6.70($ SD 3.71$)(3 ; 33)$ & 6.07 (SD 2.69) (3;21) & $0.069^{c}$ \\
\hline \multicolumn{4}{|l|}{ NTMC } \\
\hline \multicolumn{4}{|l|}{ Minor } \\
\hline Number of cases (\%) & $85(56.3 \%)$ & $21(36.8 \%)$ & \multirow[t]{4}{*}{$0.028^{\mathrm{a}^{*}}$} \\
\hline Loss of reduction (\%) & $4(4.7 \%)$ & $3(14.3 \%)$ & \\
\hline Fracture collapse $>1 \mathrm{~cm}$ & $67(78.8 \%)$ & $11(52.4 \%)$ & \\
\hline Both & $14(16.5 \%)$ & 7 (33.3\%) & \\
\hline Weeks (average) ${ }^{2}$ & $5.62(S D 2.27)(0.86 ; 17.14)$ & 5.42 (SD 1.02) (3.86;8) & $0.815^{c}$ \\
\hline \multicolumn{4}{|l|}{ Major } \\
\hline Number of cases (\%) & $8(5.29 \%)$ & $3(5.26 \%)$ & \multirow[t]{9}{*}{$1.0^{\mathrm{a}}$} \\
\hline Early cut-out (\%) & $4(50 \%)$ & $3(100 \%)$ & \\
\hline Late cut-out (\%) & $1(12.5 \%)$ & $0(0 \%)$ & \\
\hline Cut-in (\%) & $0(0 \%)$ & $0(0 \%)$ & \\
\hline Cut-through (\%) & $1(12.5 \%)$ & $0(0 \%)$ & \\
\hline Breakage (\%) & $0(0 \%)$ & $0(0 \%)$ & \\
\hline Pull-out (\%) & $0(0 \%)$ & $0(0 \%)$ & \\
\hline Osteonecrosis (\%) & $1(12.5 \%)$ & $0(0 \%)$ & \\
\hline Pseudo-arthrosis (\%) & $1(12.5 \%)$ & $0(0 \%)$ & \\
\hline Weeks (average) ${ }^{3}$ & $5.8(S D 4.23)(2.14 ; 12.86)$ & 4.5 (SD .30) (4.29;4.71) & $0.699^{c}$ \\
\hline \multicolumn{4}{|l|}{ Total } \\
\hline Number of cases (\%) & $93(61,6 \%)$ & $24(42.1 \%)$ & $0.012^{\mathrm{a}^{*}}$ \\
\hline Weeks (average) $)^{2,3}$ & 5.63 (SD 2.39) $(0.86 ; 17.14)$ & 5.34 (SD 1.02) (3.86;8) & $0.938^{c}$ \\
\hline \multicolumn{4}{|l|}{ Dynamisation } \\
\hline Number of cases (\%) & & $12(21.1 \%)$ & - \\
\hline Weeks (average) & & $5.42(S D 2.06)(1 ; 8)$ & - \\
\hline \multicolumn{4}{|l|}{ Other complications } \\
\hline \multicolumn{4}{|l|}{ IAFF } \\
\hline Number of cases (\%) & $8(5.3 \%)$ & $2(3.5 \%)$ & $0.731^{\mathrm{a}}$ \\
\hline Weeks (average) & 4.12 (SD 10.23) (0.29;29.43) & $5.36($ SD 6.57) $(0.71 ; 10)$ & $0.188^{c}$ \\
\hline \multicolumn{4}{|l|}{ Lateral thigh pain } \\
\hline Number of cases $(\%)^{4}$ & $8(5.5 \%)$ & $3(5.5 \%)$ & $1.0^{\mathrm{a}}$ \\
\hline Weeks (average) ${ }^{4}$ & 30.01 (SD 43.25) (2.85;117.14) & 27.14 (SD 22.69) (7.86;52.14) & $0.414^{c}$ \\
\hline
\end{tabular}

Tests: ${ }^{a}$ Fisher's exact test. ${ }^{c}$ Mann-Whitney $U$ test

${ }^{1}$ Excluding major complications preventing consolidation (five cases of early cut-out and one case of pseudo-arthrosis)

2 Excluding "late" diagnoses (three cases)

${ }^{3}$ Excluding "late" diagnoses (four cases: one late cut-out; one late cut-through; one osteonecrosis and one pseudo-arthrosis)

${ }^{4}$ Excluding new trauma or IAAF (ten cases)

\section{Mobility}

Statistically significant differences were detected only at the moment of discharge; fewer patients needed two aids per frame in DN. However, during standardised follow-up, there were no statistically significant differences (Fig. 2).

\section{Long-term survival}

Long-term survival is similar in both distal locking types $(P=0.874)$, after almost 6 years follow-up (Fig. 3). 


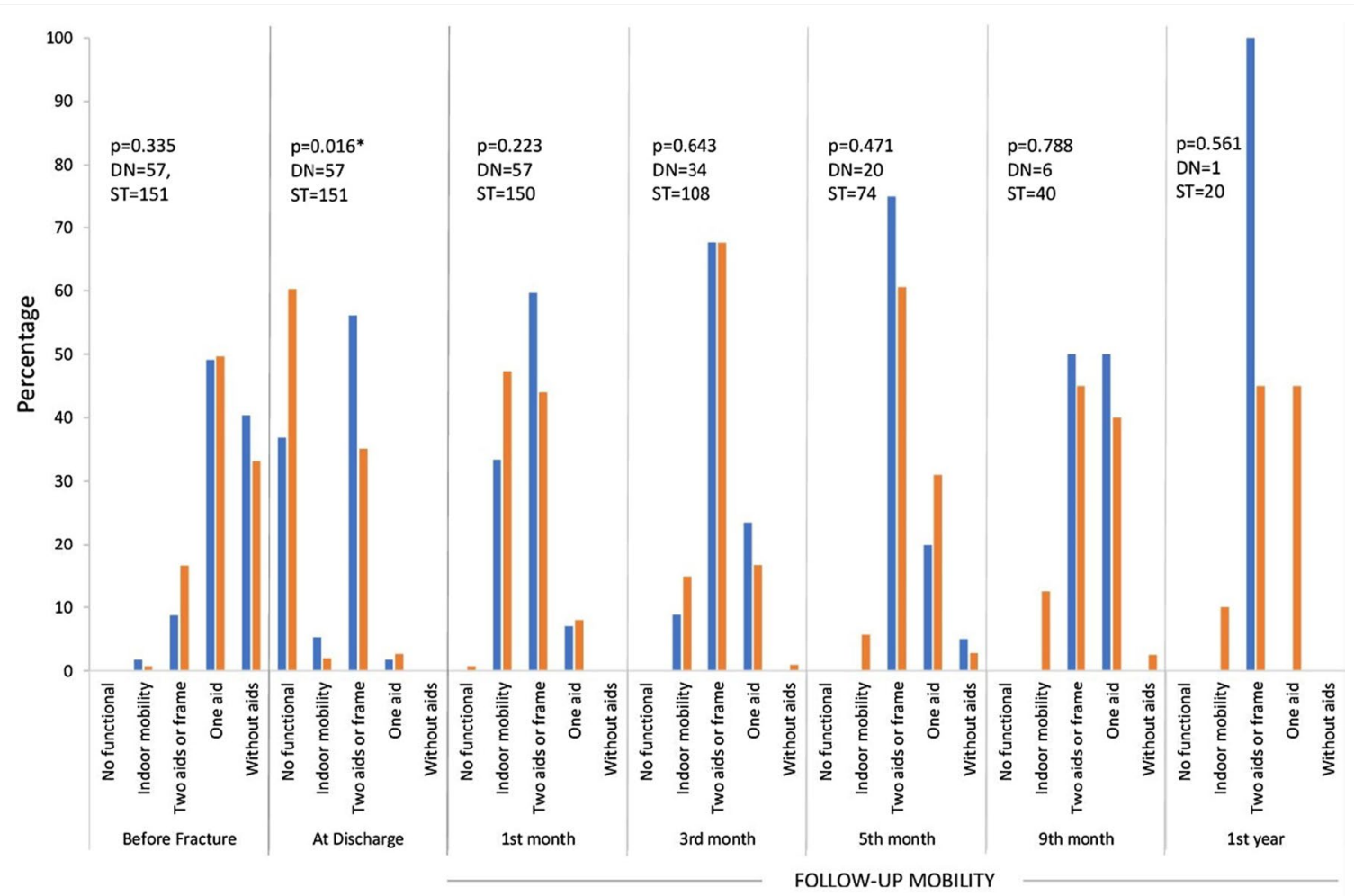

Fracture Mobility Score (FMS) $\square$ DN $\square$ ST

Fig. 2 Patients' mobility (Fisher's exact test). FMS, Fracture Mobility Score

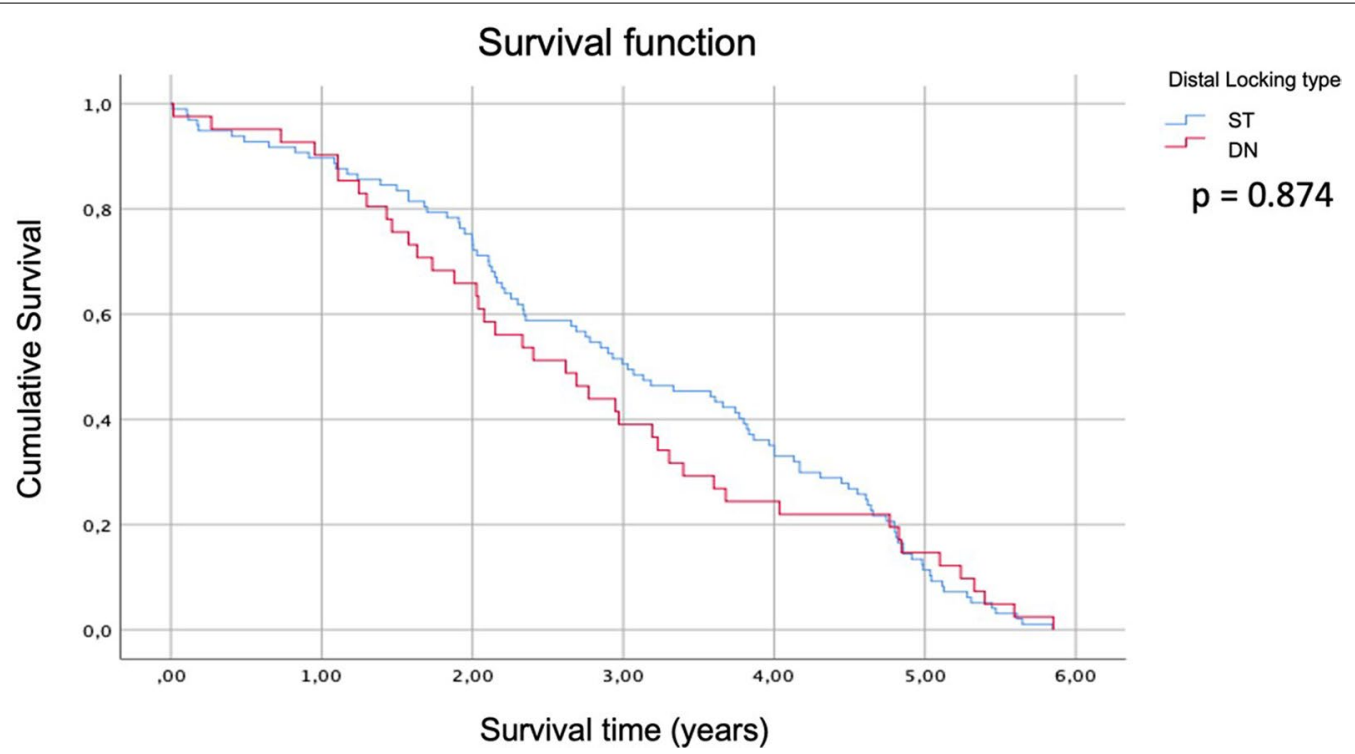

Fig. 3 Patients'survival 


\section{Discussion}

Controversy regarding distal locking in short nailing continues, mainly concerning "when and how". Ozkan et al. [51,52] do not approve of it in stable fractures, given shorter time, less surgical bleeding, and fewer intra-operative complications. On the contrary, its supporters stress lower bell-clapper effect, higher rotation stability, and latest designs reducing intra-operative and post-operative complications [39].

Distal locking is indicated in all unstable fractures. However, to date, classifications have no prognostic value, perhaps because they do not evaluate intra-operative and post-operative stability. Evans [20] suggested the importance of the internal cortical layer to transform an unstable fracture into a stable one, but Jensen determined the main fragments [29]. AO/OTA 2007 classification [42], used mainly for research purposes, has a high interobserver variability [54]. A new version (2018) has been developed with standardised projections and marking the role of the lateral wall, but it has scarce practical application. It maintains pure basicervical fractures, but independently of transcervical ones (from 31B2.1 to 31B3) [45]. Massoud considered AO/OTA 2007 A1.1 and all A2 types as "basicervical-equivalent", because their disrotation tendency [44].

Our usual practice shows a clear trend of DN locking significantly more often in stable patterns belonging to the three classifications mentioned, and of ST locking in unstable patterns. However, most of the few cases considered as "pure" basicervical were DN, probably due to traditionally considering as benign a pure pattern in two fragments. Use of distal locking in short nails is standard practice in unstable 31A3 or reverse obliquity fractures, and in those whose subtrochanteric extension indicates it [9]. Influence of position is only a theoretically higher rigidity of "in vitro" ST implants [35]. In our hospital, the use of distal locking is practically systematic (98.84\%), considering all osteoporosis cases, independent of the pattern or the stability of the fracture.

Consolidation of ECF with nails is estimated in about $95 \%$ of cases $[2,5]$; the rest are described as complications. However, there are some major mechanical complications that do not prevent consolidation. By applying these principles, our results have been better than the previous ones.

Description and naming of complications is still unclear and not universally accepted. Instrumental improvements have reduced and changed their spectrum, as described by Bojan [6] and Ehlinger [19].

Cut-out is the paradigm of major complications, mostly those based on cephalic screws [28]. Out of the 11 major complications, 8 are cut-out cases. Initial literature review suggested that the incidence of cut-out was up to $12.6 \%$ with the Richard's sliding hip screw [15]. However, it has decreased to less than $8 \%$ from 2004 , and it is currently estimated to be $1.6-4.3 \%$ [3]. This study concluded an incidence of $3.84 \%$ in the ST and $5.26 \%$ in the DN. Minimising cut-out dates back to a long time ago [19]. A better implant design [46], and improvement in the learning curve [36] and in the placement of the cephalic device, essential after Baumgaertner's work [4], may explain the results. From the latter, it is accepted that tip-apex distance (TAD) $<25 \mathrm{~mm}$ is a protection factor, with inter-observer reliability [31]. The rest of them have not proved to be so reliable. The distal tip in the centre-centre position seems to be protective too (Cleveland and Bosworth [14]), with no consensus on peripheral positions. These factors are similar in both types, as well as Fogagnolo's classification [24]. Seven out of the eight were early. Bojan [7] suggests that there could be an underlying biological problem in late ones. Although we excluded confirmed pathological fractures, in our late cut-out case local vascularisation could have been compromised by two cerclage wires. Like others [6], we consider that cut-out is the result of unfavourable biological and insufficient mechanical conditions (reduction quality, osteosynthesis accuracy and post-operative stability). All early cut-out cases occurred in potentially more rigid systems (ST and non-dynamised DN). Neither have we observed other major complications such as cut-in [65] or pull-out [58], which are relatively frequent (5-8\%) in cephalic helical blade devices. With hardly any case reports on the former [56] and almost no references of pull-out, the latest would be related to surgical technique errors [23] because design and tightening of the set screw prevent it. Theoretic biomechanical helical blade superiority is harmed by its migration "in vivo" due to the lack of set screw, an aspect that was attempted to be corrected in subsequent developments [33]. Nail breakage, which is currently an exceptional complication, was not observed either [25]. There are no differences in major complications, probably due to the scarce incidence recorded.

More minor complications were detected in ST. Most relevant is fracture collapse, linked to Trendelenburg gait and already reported with DHS [18] or PFN-A (Proximal Femoral Nail Anti-Rotation) in up to $15 \%$ of cases [60]. Protrusion of material into fascia lata and/or the loss of femoral offset due to back-out could explain this. It is unknown at what distance it starts being relevant, although $1 \mathrm{~cm}$ seems to have been accepted [21, 66]. This is why we chose said limit. The second-most relevant complication is loss of reduction associated with significant shortening and, finally, isolated loss of reduction. Minimising these could improve our patients' gait, and therefore their quality of life. 
Total number of complications is greater in ST than in $\mathrm{DN}$, due to the higher relative proportion of minor ones. Subsequent studies must determine if unstable patterns or rigid fixation systems are decisive factors. Most studies deal with EMC [31], and we approve their importance, so average detection was around 5 weeks post-surgery.

Incidence of IAFF is very similar to previously reported [41] and clearly superior to the recent Norwegian series [27], although the latter involved re-interventions with short and long nails. IAFF could be considered as a possible risk factor for cut-out.

Reported lateral thigh pain is within previously observed ranges [16, 27]. It could be related to soft tissue irritation (iliotibial band) based on back-out or loss of reduction. All our cases are associated to ST or DN systems that were not dynamised, and in $>50 \%$ of cases they coincide with significant shortening.

Dynamisation was observed in less than a quarter of cases and always before 2 months. After the corresponding bibliographic review, we have not found any other work that reviews this aspect. It would be convenient, therefore, to go deeper into the reasons that give rise to this phenomenon.

This study did not allow immediate tolerated PWB for all, but we only detected statistically significant differences at the time of discharge, in favour of DN according to the FMS [62]. We emphasise that DN is associated with stable fracture patterns, and also surgical technique recommends ST in unstable ones. Distal locking does not seem to influence the final mobility, regardless of the time of started effective loading. Most of the current studies allow immediate partial or total weight bearing at discharge [61, 64], based on higher theoretic loads while lying down [49], but despite systemic benefits for the patient, its influence on NTMC is unclear [38]. On the other hand, many of them also do not indicate at what time the load allowed was effective, the protocol used, or its duration, with great uncertainty in this topic [37].

There is no previous literature about long-term security in distal locking. As expected, its type does not influence the overall survival over 5 years.

Until present, this is the first study which implemented a systematic follow-up until endpoint using the same nail. The majority of confound factors were controlled, including age, sex, comorbidity, main pre-operative classifications, weight bearing and mobility, but until now we do not have a useful prognosis classification. We did not find differences in consolidation, but we found important differences in NTMC, which was notably lower in DN. As static locking may present more minor complications, we could rethink their use. Thus, ECF with adequate stability and contact after implant, in which significant caput-collum shortening is not expected, could benefit from static distal locking. On the contrary, in unstable ECF after osteosynthesis, a theoretical less rigid set-up with dynamic distal locking maybe would be more desirable, with potential for controlled fracture collapse. These findings contradict previously described surgical technique.

A small percentage of distal dynamic locks dynamised, and all occurred relatively early, an aspect that will need to be explored further. As suspected, infection does not seem to be influenced, but it is interesting that lateral thigh pain cases occur in the stiffer assemblies. Long-term survival is the same, implying safety in both types.

Our retrospective non-randomised design implies some peri-operative differences, as well as the exclusion of UL cases. However, we have not found any previous research which studied the long-term outcomes. Thirty-seven (17.7\%) patients did not reach the endpoint. Most were deaths, an expected percentage due to the characteristics of the sample.

\section{Conclusions}

Any type of distal locking seems to be safe with Gamma3T. Consolidation was higher than $95 \%$ at 3 months in both groups, even sometimes when major complications were present. All NTMC were usually early (EMC) and occurred between the fifth and sixth weeks. Cut-out was the most frequent major complication, whereas other complications typically from helical blades systems were exceptional, which is a crucial advantage. ST tends to be related to more minor mechanical complications, especially significant backout. There were no differences in IAFF but this may be related to cut-out, and lateral thigh pain can be related with fracture collapse. Less than $25 \%$ of the DN were indeed dynamised, and never in more than 2 months. Mobility was better at discharge only in $\mathrm{DN}$ ones, probably because of the theoretic higher stability perceived by surgeons. Long-term survival was similar.

\section{Abbreviations}

ECF: Extracapsular fracture; DHS: Dynamic Hip Screw; AO/OTA: AO Foundation/Orthopaedic Trauma Association; NTMC: Non-traumatic mechanical complications; ST: Static locking mode; DN: Dynamic locking mode; UL: Unlocked mode; PLD: Proximal locking device; FMS: Fracture Mobility Score; PWB: Partial weight bearing; EMC: Early mechanical complications; LMC: Late mechanical complications; TAD: Tip-apex distance; IAFF: Infection after fracture fixation; ASA: American Society of Anesthesiologists; APT: Anti-platelet therapy; ACT: Anti-coagulant therapy; PFN-A: Proximal Femoral Nail Anti-Rotation.

\section{Acknowledgements}

We thank Mrs. María Teresa Prendes-González, Secretary of the Department of Trauma and Orthopaedic Surgery, for her valuable support in data collection and Mr. Ángel Sánchez-Hernández, Ph.D. in Mathematics, for his valuable support with source data handling and database improvements. 


\section{Author's contributions}

$\mathrm{CH}-\mathrm{P}$ was involved in the conception and design of the study and oversaw and provided quality assurance on all study output. CH-P, JAS-S and JAM-C were involved in the conception and design of the study and drafted the manuscript. JMG-G and CFS-V assisted in statistical analysis. CP-H and LR-P revised the article critically for important intellectual content. All authors read and approved the final manuscript.

\section{Funding}

Not applicable.

\section{Availability of data and materials}

Datasets generated and analysed during the current study are not publicly available because data are not public, but they are available from the first author on reasonable request.

\section{Declarations}

\section{Ethics approval and consent to participate}

The present study was approved by the Institutional Review Board (Comité de Ética del área de Salud de Salamanca, reference code: PI2020 03 467), and it is in accordance with ethical standards laid down in Declaration of Helsinki (1964) and its later amendments.

\section{Consent for publication}

Manuscript does not contain any individual person's data in any form.

\section{Competing interests}

The authors declare that they have no competing interests.

\section{Author details}

'Department of Trauma and Orthopaedic Surgery, Hospital Universitario de Salamanca, Pso. San Vicente 58-182, 37004 Salamanca, Spain. ${ }^{2}$ Department of Radiology, Hospital Universitario de Salamanca, Pso. San Vicente 58-182, 37004 Salamanca, Spain. ${ }^{3}$ Department of Sociology, Universidad Pablo de Olavide, Crta. de Utrera Km. 1, 41013 Sevilla, Spain. ${ }^{4}$ Department of Statistics, Faculty of Medicine, Universidad de Salamanca, Campus Miguel de Unamuno, Avda. Alfonso X el Sabio s/n, 37007 Salamanca, Spain. ${ }^{5}$ Department of Geriatrics, Hospital Universitario de Salamanca, Pso. San Vicente 58-182, 37004 Salamanca, Spain. ${ }^{6}$ Department of Trauma and Orthopaedic Surgery, Hospital Universitario 12 de Octubre, Avda. de Córdoba, s/n, 28041 Madrid, Spain. ${ }^{7}$ Department of Preventive Medicine and Public Health, Faculty of Medicine, Universidad de Salamanca, Campus Miguel de Unamuno, Avda. Alfonso X el Sabio s/n, 37007 Salamanca, Spain.

Received: 12 May 2021 Accepted: 31 October 2021

Published online: 26 November 2021

\section{References}

1. Abrahamsen B, van Staa T, Ariely R, Olson M, Cooper C (2009) Excess mortality following hip fracture: a systematic epidemiological review. Osteoporos Int 20:1633-1650

2. Aguado-Maestro I, Escudero-Marcos R, García-García JM, Alonso-García N, Pérez-Bermejo DD, Aguado-Hernández HJ, Nistal-Rodríguez J, GarcíaAlonso M (2013) Results and complications of pertrochanteric hip fractures using an intramedullary nail with a helical blade (proximal femoral nail antirotation) in 200 patients. Rev Esp Cir Ortop Traumatol 57:201-207

3. Aktselis I, Papadimas D, Fragkomichalos E, Deligeorgis A, Kokoroghiannis C (2012) Intramedullary nailing of trochanteric fractures - operative technical tips. Injury 43:961-965

4. Baumgaertner MR, Curtin SL, Lindskog DM, Keggi JM (1995) The value of the tip-apex distance in predicting failure of fixation of peritrochanteric fractures of the hip. J Bone Joint Surg Am 77:1058-1064

5. Bellabarba C, Herscovici D, Ricci WM (2000) Percutaneous treatment of peritrochanteric fractures using the gamma nail. Clin Orthop Relat Res. 375:30-42
6. Bojan AJ, Beimel C, Speitling A, Taglang G, Ekholm C, Jönsson A (2010) 3066 consecutive Gamma Nails. 12 years experience at a single centre. BMC Musculoskelet Disord. 11:133

7. Bojan AJ, Beimel C, Taglang G, Collin D, Ekholm C, Jönsson A (2013) Critical factors in cut-out complication after gamma nail treatment of proximal femoral fractures. BMC Musculoskelet Disord 14:1

8. Bretherton CP, Parker MJ (2016) Femoral medialization, fixation failures, and functional outcome in trochanteric hip fractures treated with either a sliding hip screw or an intramedullary nail from within a randomized trial. J Orthop Trauma 30:642-646

9. Caiaffa V, Vicenti G, Mori C, Panella A, Conserva V, Corina G, Scialpi L, Abate A, Carrozzo M, Petrelli L, Picca G, Aloisi A, Rollo G, Filipponi M, Freda V, Pansini A, Puce A, Solarino G, Moretti B (2016) Is distal locking with short intramedullary nails necessary in stable pertrochanteric fractures? A prospective, multicentre, randomised study. Injury. 47:S98-S106

10. Chan KC, Gill GS (2000) Cemented hemiarthroplasties for elderly patients with intertrochanteric fractures. Clin Orthop Relat Res. 371:206-215

11. Charlson M, Szatrowski TP, Peterson J, Gold J (1994) Validation of a combined comorbidity index. J Clin Epidemiol 47:1245-1251

12. Charlson ME, Pompei $P$, Ales KL, MacKenzie CR (1987) A new method of classifying prognostic comorbidity in longitudinal studies: development and validation. J Chronic Dis 40:373-383

13. Ciaffa V, Vicenti G, Mori CM, Panella A, Conserva V, Corina G, Scialpi L, Speciale M, Fraccascia A, Picca G, Carrozzo M, Leone A, Morizio A, Abate A, Petrelli L, Aloisi A, Rollo G, Filipponi M, Freda V, Pansini A, Puce A, De Gabriele S, Solarino G, Moretti B (2018) Unlocked versus dynamic and static distal locked femoral nails in stable and unstable intertrochanteric fractures. A prospective study. Injury 49(Suppl 3):S19-S25

14. Cleveland M, Bosworth DM, Thompson FR, Wilson HJ Jr, Ishizuka T (1959) A ten-year analysis of intertrochanteric fractures of the femur. J Bone Jt Surg. 41:1399-1408

15. Davis TR, Sher JL, Horsman A, Simpson M, Porter BB, Checketts RG (1990) Intertrochanteric femoral fractures. Mechanical failure after internal fixation. J Bone Jt Surg Br. 72:26-31

16. Docquier PL, Manche E, Autrique JC, Geulette B (2002) Complications associated with gamma nailing. A review of 439 cases. Acta Orthop Belg. 68:251-257

17. Doppelt SH (1980) The sliding compression screw - today's best answer for stabilization of intertrochanteric hip fractures. Orthop Clin North Am 11:507-523

18. Dujardin FH, Benez C, Polle G, Alain J, Biga N, Thomine JM (2001) Prospective randomized comparison between a dynamic hip screw and a miniinvasive static nail in fractures of the trochanteric area: preliminary results. J Orthop Trauma 15:401-406

19. Ehlinger M, Favreau H, Eichler D, Adam P, Bonnomet F (2020) Early mechanical complications following fixation of proximal femur fractures: from prevention to treatment. Orthop Traumatol Surg Res 106:S79-S87

20. Evans $E$ (1949) The treatment of trochanteric fractures of the femur. J Bone Jt Surg Br 31:190-203

21. Fang C, Gudushauri P, Wong TM, Lau TW, Pun T, Leung F (2016) Increased fracture collapse after intertrochanteric fractures treated by the dynamic hip screw adversely affects walking ability but not survival. Biomed Res Int 2016:4175092

22. Fitz-Henry J (2011) The ASA classification and peri-operative risk. Ann R Coll Surg Engl 93:185-187

23. Flint JH, Sanchez-Navarro CF, Buckwalter JA, Marsh JL (2010) Intrapelvic migration of a gamma nail lag screw: review of the possible mechanisms. Orthopedics. 33:1-5

24. Fogagnolo F, Kfuri M, Paccola CA (2004) Intramedullary fixation of pertrochanteric hip fractures with the short AO-ASIF proximal femoral nail. Arch Orthop Trauma Surg 124:31-37

25. Gaebler C, Stanzl-Tschegg S, Tschegg EK, Kukla C, Menth-Chiari WA, Wozasek GE, Heinz T (1999) Implant failure of the gamma nail. Injury 30:91-99

26. Herrera A, Martínez AA, Ferrandez L, Gil E, Moreno A (2006) Epidemiology of osteoporotic hip fractures in Spain. Int Orthop 30:11-14

27. Horner NS, Samuelsson K, Solyom J, Bjørgul K, Ayeni OR, Östman B (2017) Implant-related complications and mortality after use of short or long gamma nail for intertrochanteric and subtrochanteric fractures: a prospective study with minimum 13-year follow-up. JB JS Open Access. 2:e0026 
28. Ibrahim I, Appleton PT, Wixted JJ, DeAngelis JP, Rodriguez EK (2019) Implant cut-out following cephalomedullary nailing of intertrochanteric femur fractures: are helical blades to blame? Injury 50:926-930

29. Jensen JS (1980) Classification of trochanteric fractures. Acta Orthop Scand 51:803-810

30. Kanis JA, Oden A, Johnell O, De Laet C, Jonsson B, Oglesby AK (2003) The components of excess mortality after hip fracture. Bone 32:468-473

31. Kawaguchi S, Sawada K, Nabeta Y (1998) Cutting-out of the lag screw after internal fixation with the Asiatic gamma nail. Injury 29:47-53

32. Kim SY, Kim YG, Hwang JK (2005) Cementless calcar-replacement hemiarthroplasty compared with intramedullary fixation of unstable intertrochanteric fractures. A prospective, randomized study. J Bone Joint Surg Am. 87:2186-2192

33. Koyuncu S, Altay T, Kayali C, Ozan F, Yamak K (2015) Mechanical failures after fixation with proximal femoral nail and risk factors. Clin Interv Aging 10:7

34. Kumar R, Singh RN, Singh BN (2012) Comparative prospective study of proximal femoral nail and dynamic hip screw in treatment of intertrochanteric fracture femur. J Clin Orthop Trauma 3:28-36

35. Kuzyk PR, Shah S, Zdero R, Olsen M, Waddell JP, Schemitsch EH (2012) A biomechanical comparison of static versus dynamic lag screw modes for cephalomedullary nails used to fix unstable peritrochanteric fractures. J Trauma Acute Care Surg 72:E65-70

36. Li S, Chang SM, Niu WX, Ma H (2015) Comparison of tip apex distance and cut-out complications between helical blades and lag screws in intertrochanteric fractures among the elderly: a meta-analysis. J Orthop Sci 20:1062-1069

37. Lizano-Díez X, Keel MJB, Siebenrock KA, Tey M, Bastian JD (2020) Rehabilitation protocols in unstable trochanteric fractures treated with cephalomedullary nails in elderly: current practices and outcome. Eur J Trauma Emerg Surg 46:1267-1280

38. Lobo-Escolar A, Joven E, Iglesias D, Herrera A (2010) Predictive factors for cutting-out in femoral intramedullary nailing. Injury 41:1312-1316

39. López-Vega M, Gil-Monzó ER, Rodrigo-Pérez JL, López-Valenciano J, Salanova-Paris RH, Peralta-Nieto J, Morales-Suárez MM (2015) Randomized prospective study on the influence distal block and Gamma 3 nail on the treatment of intertrochanteric fractures of femur. Rev Esp Cir Ortop Traumatol 59:26-35

40. Mahoney F, Barthel D (1965) Functional evaluation: the Barhel index. Md State Med J 14:61-65

41. Malik MH, Harwood P, Diggle P, Khan SA (2004) Factors affecting rates of infection and nonunion in intramedullary nailing. J Bone Jt Surg Br 86:556-560

42. Marsh JL, Slongo TF, Agel J, Broderick JS, Creevey W, DeCoster TA, Prokuski L, Sirkin MS, Ziran B, Henley B, Audigé L (2007) Fracture and dislocation classification compendium - 2007: Orthopaedic Trauma Association classification, database and outcomes committee. J Orthop Trauma 21:S1-133

43. Martínez de la Iglesia J, Dueñas Herrero R, Onís Vilches MC, Aguado Taberné C, Albert Colomer C, Luque Luque R (2001) Spanish language adaptation and validation of the Pfeiffer's questionnaire (SPMSQ) to detect cognitive deterioration in people over 65 years of age. Med Clin. 117:129-134

44. Massoud El (2010) Fixation of basicervical and related fractures. Int Orthop 34:577-582

45. Meinberg EG, Agel J, Roberts CS, Karam MD, Kellam JF (2018) Fracture and dislocation classification compendium-2018. J Orthop Trauma 32(Suppl 1):S1-S170

46. Mereddy P, Kamath S, Ramakrishnan M, Malik H, Donnachie N (2009) The AO/ASIF proximal femoral nail antirotation (PFNA): a new design for the treatment of unstable proximal femoral fractures. Injury 40:428-432

47. Metsemakers WJ, Morgenstern M, McNally MA, Moriarty TF, McFadyen I, Scarborough M, Athanasou NA, Ochsner PE, Kuehl R, Raschke M, Borens O, Xie Z, Velkes S, Hungerer S, Kates SL, Zalavras C, Giannoudis PV, Richards RG, Verhofstad MHJ (2018) Fracture-related infection: a consensus on definition from an international expert group. Injury 49:505-510

48. Neuerburg C, Förch S, Gleich J, Böcker W, Gosch M, Kammerlander C, Mayr E (2019) Improved outcome in hip fracture patients in the aging population following co-managed care compared to conventional surgical treatment: a retrospective, dual-center cohort study. BMC Geriatr 19:330
49. Nordin M, Frankel V (1989) Biomechanics of the hip. In: Nordin M, Frankel $\checkmark$ (eds) Basic biomechanics of the musculoskeletal system. Lea \& Febiger, Malvern, pp 135-161

50. Nuti R, Brandi ML, Isaia G, Tarantino U, Silvestri S, Adami S (2009) New perspectives on the definition and the management of severe osteoporosis: the patient with two or more fragility fractures. J Endocrinol Invest 32:783-788

51. Ozkan K, Turkmen I, Sahin A, Yildiz Y, Erturk S, Soylemez MS (2015) A biomechanical comparison of proximal femoral nails and locking proximal anatomic femoral plates in femoral fracture fixation. A study on synthetic bones. Indian J Orthop 49:347-351

52. Ozkan K, Unay K, Demircay C, Cakir M, Eceviz E (2009) Distal unlocked proximal femoral intramedullary nailing for intertrochanteric femur fractures. Int Orthop 33:1397-1400

53. Page PR, Lord R, Jawad A, Dawe E, Stott P, Rogers B, Gill R (2016) Changing trends in the management of intertrochanteric hip fractures-a single centre experience. Injury 47:1525-1529

54. Pervez H, Parker MJ, Pryor GA, Lutchman L, Chirodian N (2002) Classification of trochanteric fracture of the proximal femur: a study of the reliability of current systems. Injury 33:713-715

55. Pfeiffer E (1975) A short portable mental status questionnaire for the assessment of organic brain deficit in elderly patients. J Am Geriatr Soc 23:433-441

56. Pinheiro AC, Alpoim B, Félix A, Alves C, Sousa C, Rodrigues A (2016) Medial migration of the intramedullary Gamma 3 nail-a case report. Rev Bras Ortop 51:720-724

57. Reindl R, Harvey EJ, Berry GK, Rahme E, Canadian Orthopaedic Trauma Society (COTS). (2015) Intramedullary versus extramedullary fixation for unstable intertrochanteric fractures: a prospective randomized controlled trial. J Bone Joint Surg Am 97:1905-1912

58. Simmermacher RK, Ljungqvist J, Bail H, Hockertz T, Vochteloo AJ, Ochs U, Werken C, AO - PFNA studygroup (2008) The new proximal femoral nail antirotation (PFNA) in daily practice: results of a multicentre clinical study. Injury 39:932-939.

59. Skála-Rosenbaum J, Bartonícek J, Bartoska R (2010) Is distal locking with IMHN necessary in every pertrochanteric fracture? Int Orthop 34:1041-1047

60. Soucanye de Landevoisin E, Bertani A, Candoni P, Charpail C, Demortiere E (2012) Proximal femoral nail antirotation (PFN-ATM) fixation of extracapsular proximal femoral fractures in the elderly: retrospective study in 102 patients. Orthop Traumatol Surg Res. 98:288-295

61. Vaquero J, Munoz J, Prat S, Ramirez C, Aguado HJ, Moreno E, Perez MD (2012) Proximal femoral nail antirotation versus Gamma3 nail for intramedullary nailing of unstable trochanteric fractures. A randomised comparative study. Injury 43(Suppl 2):S47-54

62. Voeten SC, Nijmeijer WS, Vermeer M, Schipper IB, Hegeman JH, DHFA Taskforce study group (2020) Validation of the Fracture Mobility Score against the Parker Mobility Score in hip fracture patients. Injury. 51:395-399

63. Vopat BG, Kane PM, Truntzer J, McClure P, Paller D, Abbood E, Born C (2014) Is distal locking of long nails for intertrochanteric fractures necessary? A clinical study. J Clin Orthop Trauma 5:233-239

64. Xu Y, Geng D, Yang H, Wang X, Zhu G (2010) Treatment of unstable proximal femoral fractures: comparison of the proximal femoral nail antirotation and gamma nail 3. Orthopedics 33:473

65. Yam M, Kang BJ, Chawla A, Zhang W, Way LG, Xavier RPA, Park DH, Yeo NEM, Howe TS, Kwek EBK (2020) Cephalomedullary blade cut-ins: a poorly understood phenomenon. Arch Orthop Trauma Surg. 140(12):1939-45

66. Zlowodzki M, Ayeni O, Ayieni O, Petrisor BA, Bhandari M (2008) Femoral neck shortening after fracture fixation with multiple cancellous screws: incidence and effect on function. J Trauma 64:163-169

\section{Publisher's Note}

Springer Nature remains neutral with regard to jurisdictional claims in published maps and institutional affiliations. 